\title{
NUMERICAL PREDICTION OF WAVE PATTERNS DUE TO MOTION OF 3D BODIES BY KELVIN-HAVELOCK SOURCES
}

\author{
Hassan Ghassemi, Prof. \\ Isar Ghamari, Ph.D. \\ Arash Ashrafi, M.Sc. \\ AmirKabir University of Technology, Iran
}

\begin{abstract}
This paper discusses the numerical evaluation of the hydrodynamic characteristics of submerged and surface piercing moving bodies. Generally, two main classes of potential methods are used for hydrodynamic characteristic analysis of steady moving bodies which are Rankine and Kelvin-Havelock singularity distribution. In this paper, the KelvinHavelock sources are used for simulating the moving bodies and then free surface wave patterns are obtained. Numerical evaluation of potential distribution of a Kelvin-Havelock source is completely presented and discussed. Numerical results are calculated and presented for a $2 \mathrm{D}$ cylinder, single source, two parallel moving source, sphere, ellipsoid and standard Wigley hull in different situation that show acceptable agreement with results of other literatures or experiments.
\end{abstract}

Keywords: Free Surface Waves, Boundary Element Method (BEM), Kelvin-Havelock Source

\section{INTRODUCTION}

A number of numerical methods for computing freesurface flows of ship forms are presented as robust and accurate on the basis of favorable comparisons between numerical predictions and experimental measurements. As a matter of fact, numerical predictions of free-surface flows about ship forms, including the steady-flow case of specific interest here, are notoriously unreliable, as is documented in Andrew et al. [1], Newman [3-4], Chen and Noblesse [4], Telste, and Noblesse [5], Hendrix and Noblesse [6]. Other trends of ship hydrodynamics including wave resistance in calm water were reviewed in Bulgarelli et al. [7]. On the other hand, some historical perspectives and reflections of ship waves were given by Tulin [8]. Compressive description on the ship resistance computations have been presented by Larrson and Baba [9]. Comparison of different approach for the ship resistance calculations carried out by Gatchell et al [10]. A 3D linear analysis of steady ship motion in deep water have presented in the Ph.D. dissertation [11]. Baar and Price also contain extensive comparisons of the authors own KelvinHavelock numerical predictions with experimental data [12].
A desingularized boundary integral method for fully nonlinear free-surface problems was described Cao et.al. [13]. An integral boundary element method (Rankine panel) to solve the flow around surface piercing hydrofoils and ships was presented by Hsin et.al. [14] as well as two iterative procedures for small and large Froude numbers were presented for fully submerged two dimensional hydrofoils under a free surface by Yasko et.al.[15]. Ghassemi et al. [16] and Ghassemi \& Kohansal [17] have presented the nonlinear generated wave pattern due to three dimensional moving bodies. More detail formulae for 2D and 3D free surface flows due to moving disturbances have been presented by Tuck et al [18], Parau \& Vanden-Broeck [19] and Uslu \& Bal [20]. Javanmardi et al worked the prediction of wave patterns at large distances from a moving body in a confined channel [21]. In order to minimize the total resistance of a ship, an optimization of the hull shape investigated by Sun et al [22] and Zakerdoost et al [23]. The total resistance is assumed to be the sum of the wave resistance computed on the basis of the thin-ship theory and the frictional resistance. Smoothness of hull lines is proved with mathematical procedure, in which differentials of the hull lines functions are analyzed. The 
wave-making resistance optimization, involving a genetic algorithm, uses Michell integral to calculate wave resistance. Recently, the computational results for KRISO Container Ship (KCS) are presented. CFD analyses are performed to simulate free surface flow around KCS by using RANS approach with success. Also, the complicated turbulent flow zone behind the ship is well simulated [24].

A major difficulty of the Kelvin-Havelock approach resides in the mathematical complexity of the corresponding Green function, often referred to as the Kelvin-Havelock source. Indeed, the complexity of the Kelvin-Havelock source and the simplicity of the Rankine source no doubt are major recommendations for using the Rankine-source approach. However, the Kevin-Havelock source offers several important advantages compared with the Rankine source. In particular, the radiation condition that steady gravity waves do not exist ahead of a moving ship is automatically and exactly satisfied in the Kelvin-Havelock approach, whereas this radiation condition must be numerically simulated in the Rankine-source approach. Also, the infinite free surface must be truncated in some manner in Rankine source approach, whereas the infinite free surface is automatically reduced to a finite one in the Numann-Kelvin approach. The need for numerically simulation the radiation condition and for truncating the infinite free surface represents two basic difficulties of the Rankine-source approach. Another advantage of the Kelvin-Havelock source follows from the fact that it satisfies a linearized free surface boundary condition that provides a reasonable approximation to the exact free surface condition for many practical applications. In this case, there is no need for a free surface singularity distribution and the Kelvin-Havelock source can be used to obtain a simple approximate expression for the velocity potential of the flow about a ship that is defined explicitly in terms of the ship speed, size and shape.

In this paper, an efficient manner of evaluating KelvinHavelock source Green function are presented and then the procedure have been employed for submerged cylinder, sphere and ellipsoid and a Wigley hull. Wave pattern of the free surface are obtained and shown by the numerical method in qualitatively and quantitative. The validation of the present method is confirmed by showing good correlation with the available data.

\section{MATHEMATICAL FORMULATION OF THE PROBLEM}

A three dimensional moving body at a constant velocity $(U)$ at or beneath the surface of a fluid of infinite depth is considered. The sketch of the body and flow are given in Fig. 1. The fluid is assumed to be inviscid, incompressible and the flow to be irrotational.

It was chosen a Cartesian frame of reference moving bodies and assumed that the flow is steady. The Cartesian coordinates $(x, y, z)$ is chosen with the $z$-axis directed vertically upwards and the $x$-axis in the opposite direction of the velocity $(U)$. The equation of the free surface is denoted by $z=\eta(x, y)$.

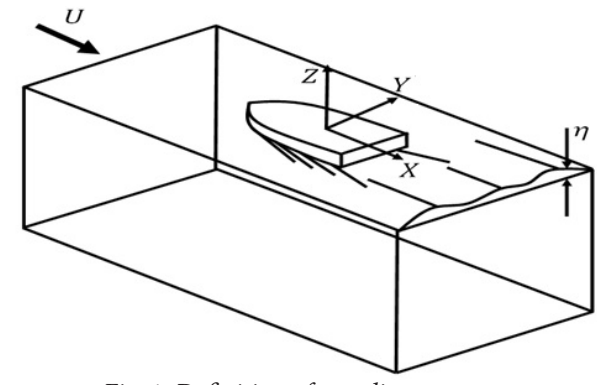

Fig. 1. Definition of coordinate system

Perturbation potential, $\varnothing$, and total potential, $\Phi$, should satisfy Laplace's equation in the fluid domain.

$$
\nabla^{2} \Phi=\nabla^{2} \emptyset=0
$$

Three boundary conditions on the free surface are given as follows:

\section{I) KINEMATIC BOUNDARY CONDITION ON THE BODY SURFACE:}

The flow should be tangent to the wetted surface of the body:

$$
\frac{\partial \emptyset}{\partial n}=-(U \hat{\imath}) \cdot \vec{n}=-U \cdot n_{x}
$$

where $\vec{n}$ is the unit normal vector to the wetted surface of the body, directed into the fluid domain.

\section{II) KINEMATIC FREE SURFACE CONDITION:}

The fluid particles should follow the free surface,

$$
\frac{D F(x, y, z)}{D t}=0 \quad \text { on } z=\eta(x, y)
$$

where $F(x, y, z)=z-\eta(x, y)$ and $\eta$ is the free surface deformation.

\section{III) DYNAMIC FREE SURFACE CONDITION:}

The pressure on the free surface should be equal to the atmospheric pressure $\left(\rho_{\text {atm }}\right)$. Applying Bernoulli's equation, the following equation can be obtained:

$$
\frac{1}{2}\left[(\nabla \varnothing)^{2}-U^{2}\right]+g \eta=0 \quad \text { on } z=\eta(x, y)
$$

where $g$ is the gravitational acceleration.

If eq. (3) and eq. (4) are combined and linearized, then the following free surface condition can be derived:

$$
\frac{\partial^{2} \emptyset}{\partial x^{2}}+k_{0} \frac{\partial \emptyset}{\partial z}=0 \quad \text { on } z=0
$$


Here, $k_{0}=\frac{g}{U^{2}}$ is the wave number.

\section{IV) RADIATION CONDITION:}

No upstream waves should occur. In order to prevent upstream waves, both the first- and second-order derivatives of perturbation potential with respect to $x$ are forced to be equal to zero for the upstream region on the free surface.

$$
\frac{\partial^{2} \emptyset}{\partial x^{2}}=\frac{\partial \emptyset}{\partial x}=0 \quad \text { as } x \rightarrow-\infty
$$

\section{V) INFINITE DEPTH CONDITION:}

The perturbation potential should go to zero for infinite depth.

$$
\lim _{z \rightarrow-\infty} \nabla \emptyset \rightarrow 0
$$

Finally after computing the potential distribution on free surface, the wave elevation is computed as follows:

$$
\eta=-\frac{U}{g} \frac{\partial \emptyset}{\partial x}
$$

\section{NUMERICAL SCHEME}

Applying the integral representation for the potential function $(p)$, Green's second identity can be written as:

$$
e \phi(p)=\iint_{S}\left[\phi \frac{\partial G}{\partial n}-G \frac{\partial \phi}{\partial n}\right] d S
$$

where $e$ is a coefficient that its value depends on the position of the field point $p$ in the fluid domain. If point $p$ is placed on the boundary (body surface), then the coefficient $e$ is replaced by 0.5 . If point $p$ is placed inside and outside of the body then the value of $e$ is one and zero, respectively.

Also, $G$ is the Green function of a Kelvin-Havelock source which it will be discussed hereafter. This Green function has 3 parts and we need to be able to solve it for a sample source and then use the solution for whole body. The Green function for a source in $(x, y, z)$ which translates uniformly with speed $U$ in infinite fluid and for an observation point in $(x, y, z)$ is:

$$
\begin{gathered}
G\left(x, y, z: x_{0}, y_{0}, z_{0}\right)= \\
S(X, Y, Z)+N(X, Y, Z)+W(X, Y, Z)
\end{gathered}
$$

Term $S$ (simple term) is defined as:

$$
\begin{aligned}
& R=\sqrt{\left(x-x_{0}\right)^{2}+\left(y-y_{0}\right)^{2}+\left(z-z_{0}\right)^{2}} \\
& R^{\prime}=\sqrt{\left(x-x_{0}\right)^{2}+\left(y-y_{0}\right)^{2}+\left(z+z_{0}\right)^{2}}
\end{aligned}
$$

$$
\begin{aligned}
& R=\sqrt{\left(x-x_{0}\right)^{2}+\left(y-y_{0}\right)^{2}+\left(z-z_{0}\right)^{2}} \\
& R^{\prime}=\sqrt{\left(x-x_{0}\right)^{2}+\left(y-y_{0}\right)^{2}+\left(z+z_{0}\right)^{2}}
\end{aligned}
$$

And:

$$
(X, Y, Z)=\frac{g}{U^{2}}\left(x-x_{0}, y-y_{0}, z+z_{0}\right)
$$

Term $N$ that is known as non-oscillatory near field term is defined as [19]:

$$
N(X)=\frac{-2 v}{\pi}\left\{-\frac{1}{2 \pi} \int_{-1}^{1} \operatorname{Im} \exp (A) E_{1}(A) d t\right\}
$$

And:

$$
A=\left[Z\left(1-t^{2}\right)^{\frac{1}{2}}+Y t+i|X|\right]\left(1-t^{2}\right)^{\frac{1}{2}}
$$

$E_{1}(A)$ is the well known exponential integral which can be expressed as:

$$
E_{1}(A)=\int_{0}^{\infty} \frac{e^{-(t+A)}}{t+A} d t
$$

Finally, the term $W$ which is oscillatory far field term (or somewhere is known as wave term) represents the system of Kelvin waves trailing behind the singular point, as is indicated explicitly by the Heaviside unit step function and is expressed as:

$$
\begin{gathered}
W(X)=(-4 v) H(X) \int_{-\infty}^{+\infty} \operatorname{Im}\left\{\operatorname { e x p } \left[Z\left(1+t^{2}\right)\right.\right. \\
\left.\left.+i(X+Y t) \sqrt{1+t^{2}}\right]\right\} d t
\end{gathered}
$$

Numerical evaluation of the source potential thus involves three basic tasks corresponding to the evaluation of the simple singularity potential, the non-oscillatory near-field potential, and the wave potential. Two distinct numerical tasks must be considered for evaluating each of these potential parts. The first task is numerical evaluation of the main terms and their gradients, and the second is numerical integration of them over a flat triangle $T$.

\section{I) SIMPLE TERM:}

For evaluating the gradient of simple term it can be used the following relation:

$$
\frac{\partial}{\partial n}\left(\frac{1}{R}\right)=\frac{\vec{R} \cdot \vec{n}}{|R|^{3}}
$$

When the singular point is on the field element this term vanishes because it uses flat element and in $R$ and $n$ will be perpendicular to each other. For integrating this integrand over a flat element we can use simple Gauss method.

where: 

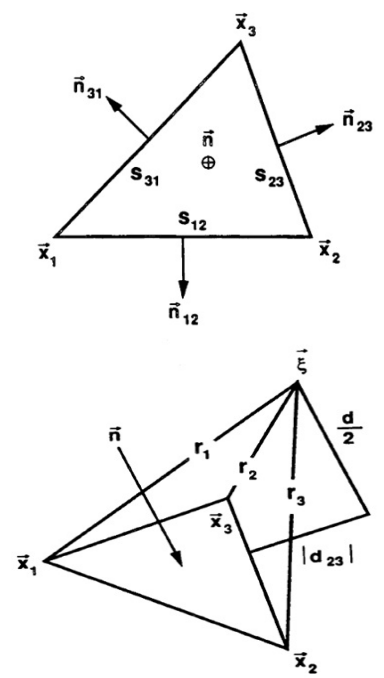

Fig. 2. Panel definition sketch

It is well known that the integration of simple term can be evaluated analytically. This integral over a flat triangular panel may be expressed in the form:

$$
\begin{gathered}
\iint_{S} \frac{1}{R} d s=d_{12} \ln \rho_{12}+d_{23} \ln \rho_{23}+d_{31} \ln \rho_{31} \\
+d\left(\tan ^{-1} t_{12}+\tan ^{-1} t_{23}+\tan ^{-1} t_{31}\right)
\end{gathered}
$$

where the terms $d_{i j}, \rho_{i j}, t_{j j}$ and $d$ are now defined:

$$
\rho_{i j}=\frac{r_{i j}-s_{i j}}{r_{i j}+s_{i j}}
$$

that $s_{i j}$ is the length of the side of the triangle $T$ between the vertices $\vec{x}_{i}$ and $\vec{x}_{j}$, as indicated in Fig. 2, and is defines as:

$$
r_{i j}=r_{i}+r_{j}
$$

where $r_{i}$ representing the distance between the calculation point $\vec{\xi}^{i}$ and the vertex $\vec{x}_{i}$ of $T$, as shown in Fig. 2 . The terms $d_{i j}$ in equation (19) are defined as:

$$
d_{i j}=\left[\vec{\xi}-\left(\vec{x}_{i}+\vec{x}_{j}\right) / 2\right] \cdot \vec{n}_{i j}
$$

And $\vec{n}_{i j}$ is the unit vector in the plane of T normal to the side of $\mathrm{T}$ between the vertices $\vec{x}_{i}$ and $\vec{x}_{j}$ and pointing outside $T$, as indicated in Fig. 2. We then have:

$$
n_{i j}=\vec{n} \times \frac{\vec{x}_{j}-\vec{x}_{i}}{s_{i j}}
$$

where $\vec{n}$ is the unit vector normal to $T$ oriented as in Fig. 2; specifically, the vertices of the panel are numbered counterclockwise when the panel is viewed in the direction of the normal vector $\vec{n}$.

It can be verified that $\left|d_{i j}\right|$ is the distance from the projection of the calculation point $\vec{\xi}$ onto the plane of $T$ to the side of T between the vertices $\vec{x}_{j}$ and $\vec{x}_{i}$, as shown in Fig. 2 . The term $d$ in eq. (19) is defined by:

$$
d=2\left|\vec{\xi}-\overrightarrow{x_{0}}\right| \cdot \vec{n}
$$

Where $\vec{x}_{0}$ is the centroid of $T$ given by:

$$
\vec{x}_{0}=\frac{\vec{x}_{1}+\vec{x}_{2}+\vec{x}_{3}}{3}
$$

It can be seen that $d$ is equal to twice the distance between $\vec{\xi}$ and the plane of T, as indicated in Fig. 2. Finally, the terms $t_{i j}$ in (19) are defined as:

$$
t_{i j}=\frac{2 s_{i j} d_{i j}}{\left[r_{i j}\left(r_{i j}+d\right)-\left(s_{i j}\right)^{2}\right]}
$$

In the particular case when the calculation point $\vec{\xi}$ is in the plane of the triangle $T$, we have $d=0$ and eq. (19) simplifies accordingly. If $\vec{\xi}$ lies on one of the three sides of $T$, say on the side between the vertices $\vec{x}_{i}$ and $\vec{x}_{j}$, we have and the contribution of the side ij in eq. (19) vanishes. If the calculation point $\vec{\xi}$ is at one of the three vertices of $T$, say at $\vec{x}_{i}$, we have both $d_{i j}=d_{i k}=0$, and the contributions of the two sides $i j$ and $k i$ in (19) vanish.

The foregoing exact analytic expressions for the simple term integral only need to be used for calculation points $\vec{\xi}$ in the vicinity of the triangle $T$. Indeed, at large and intermediate distances from $T$ the approximations can be computationally more efficient.

\section{II) OSCILLATORY NEAR FIELD TERM:}

Calculating this term is considered in Newman [2] and Telste and Noblesse [5]. The latter study presents a computationally efficient method for evaluating the function $N(X)$, using table interpolation together with two term series representations for small and large values of $R$.

The function $N(X)$ could be defined as the following alternative integrals:

$$
\begin{gathered}
N(X)=\frac{-2 v}{\pi}\left\{-\frac{1}{2 \pi} \int_{-1}^{1} \operatorname{Im} \exp (A) E_{1}(A) d t\right\}= \\
\frac{-2 v}{\pi}\left\{\frac{1}{2}\left[1-\frac{Z}{R+|X|}\right]\right. \\
+\int_{-1}^{1} \operatorname{Im}\left[\exp (A) E_{1}(A)\right. \\
\left.\left.+\ln (A)+\gamma^{\prime}\right] d t\right\}
\end{gathered}
$$

Where $E_{1}(A)$ is the exponential integration and was explained before and $\gamma^{\prime}=0.577$ is Euler's constant. The calculation domain is $-\propto \leq X, Y \leq \propto$ and $-\propto \leq Z \leq 0$.

The behavior of the function $N(X)$ in the limits $\mathrm{R} \rightarrow \propto$ and $\mathrm{R} \rightarrow 0$ is given in Telste and Noblesse [5] as: 


$$
\underset{2 \mathrm{~N} \sim \frac{1}{\mathrm{R}}+\frac{\mathrm{C}\left[1-(1+\mathrm{C})\left(\frac{\mathrm{X}}{\mathrm{R}}\right)^{2}\right]}{\mathrm{R}^{2}}}{\text { as } \mathrm{R} \rightarrow \infty \text { with } \mathrm{C}=1 / 1-\frac{\mathrm{Z}}{\mathrm{R}}}
$$

And

$$
\begin{gathered}
2 N \sim 1-\frac{Z}{R+|X|}+\frac{|X|}{2} \ln [(R+|X|) / 4] \\
+\left(\frac{|X|}{4}\right)\left[2 \gamma^{\prime}-1-\frac{\left(\frac{1}{3}\right)\left(Y^{2}-Z^{2}\right)}{(R+|X|)^{2}}\right] \\
-\frac{\left(\frac{Y}{3}\right) Y}{R+|X|}+\left(\frac{2 Z}{3}\right)\left[1-\frac{Z}{R+|X|}\right] \quad \text { as } R \rightarrow 0
\end{gathered}
$$

The transformation $(X, Y, Z) \rightarrow(\rho, \alpha, \beta)$ defined below maps the semi-infinite space into the unit cube.

$$
\begin{gathered}
\rho=\frac{\sqrt{R}}{1+\sqrt{R}} \\
\alpha=\frac{|X|}{|X|+\sqrt{Y^{2}+Z^{2}}} \\
\beta=\frac{-Z}{\sqrt{Y^{2}+Z^{2}}}
\end{gathered}
$$

The function $N^{\prime}(\rho, \alpha, \beta)$ is defines as $+N^{\prime}(\rho, \alpha, \beta)=(1+R)$ $N(\rho, \alpha, \beta)$ and now we can use a simple and computationally efficient method for approximating the function $N^{\prime}$ consists in using table interpolation based on values of the function $N^{\prime}$ at equally-spaced values of the transformed coordinates $\rho, \alpha, \beta$. A simple and computationally efficient interpolation formula is linear interpolation in each of the three independent variables $\rho, \alpha, \beta$. More precisely, let the values of the function $N^{\prime}(\rho, \alpha, \beta)$ be given at equally spaced values:

$$
\begin{aligned}
& \left(\rho_{1}=0, \rho_{2}, \ldots, \rho_{i}, \rho_{i+1}, \ldots, \rho_{N_{\rho}}=1\right) \\
& \left(\alpha_{1}=0, \alpha_{2}, \ldots, \alpha_{i}, \alpha_{i+1}, \ldots, \alpha_{N_{\alpha}}=1\right) \\
& \left(\beta_{1}=0, \beta_{2}, \ldots, \beta_{i}, \beta_{i+1}, \ldots, \beta_{N_{\beta}}=1\right)
\end{aligned}
$$

of the coordinates $\rho, \alpha, \beta$ with

$$
\begin{aligned}
& \Delta \rho=\rho_{i+1}-\rho_{i}=\frac{1}{N_{\rho}-1} \text { for } 1 \leq i \leq N_{\rho}-1 \\
& \Delta \alpha=\alpha_{j+1}-\alpha_{j}=\frac{1}{N_{\alpha}-1} \text { for } 1 \leq j \leq N_{\alpha}-1 \\
& \Delta \beta=\beta_{k+1}-\beta_{k}=\frac{1}{N_{\beta}-1} \text { for } 1 \leq k \leq N_{\beta}-1
\end{aligned}
$$

The intervals, $\left[p_{i}, p_{i+1}\right]$ and corresponding to any point $(X, Y, Z)$ can be determined directly (that is, without performing a table search) from eq. (30) and the following formulas:

$$
\begin{aligned}
& i=1+\operatorname{Int}\left[\rho\left(N_{\rho}-1\right)\right], \\
& j=1+\operatorname{Int}\left[\alpha\left(N_{\alpha}-1\right)\right], \\
& k=1+\operatorname{Int}\left[\beta\left(N_{\beta}-1\right)\right]
\end{aligned}
$$

where $\operatorname{Int}[x]$ is the largest integer less than or equal to $x$. Linear interpolation of the function $N^{\prime}(\rho, \alpha, \beta)$ is defined by:

$$
\begin{aligned}
N^{\prime}(\rho, \alpha, \beta)=\gamma[ & \mu\left(v N_{i+1, j+1, k+1}^{\prime}+\bar{v} N_{i+1, j+1, k}^{\prime}\right) \\
& +(1-\mu)\left(v N_{i+1, j, k+1}^{\prime}\right. \\
& \left.\left.+\bar{v} N_{i+1, j, k}^{\prime}\right)\right] \\
+(1-\gamma)[\mu & \left(v N_{i, j+1, k+1}^{\prime}+\bar{v} N_{i+1, j+1, k}^{\prime}\right) \\
& \left.+(1-\mu)\left(v N_{i, j, k+1}^{\prime}+\bar{v} N_{i, j, k}^{\prime}\right)\right]
\end{aligned}
$$

where, $\mu, v$ and $\bar{v}$ are given by:

$$
\begin{gathered}
\gamma=\rho\left(N_{\rho}-1\right)-\operatorname{Int}\left[\rho\left(N_{\rho}-1\right)\right], \\
\mu=\alpha\left(N_{\alpha}-1\right)-\operatorname{Int}\left[\alpha\left(N_{\alpha}-1\right)\right], \\
v=\beta\left(N_{\beta}-1\right)-\operatorname{Int}\left[\beta\left(N_{\beta}-1\right)\right], \\
\bar{v}=1-v
\end{gathered}
$$

The non-oscillatory term $N$ is now computed, and a sevenpoint Gauss method (which will be explained below) is used for integration on the triangular panels.

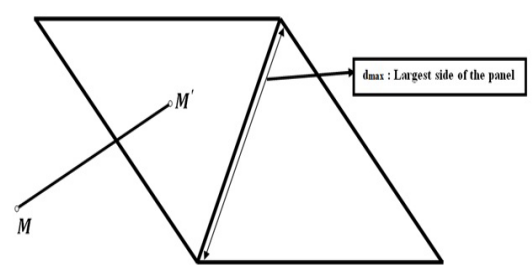

(a)

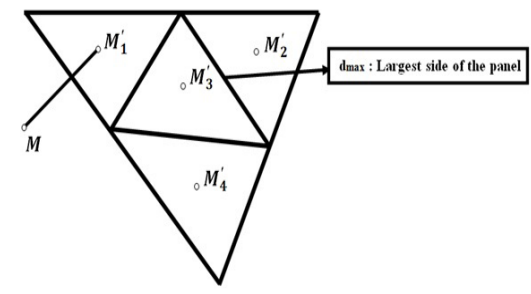

(b)

Fig.3. (a) Definition sketch for space integration. (b) Division of a triangular panel into four triangular panels

For integration of this non-oscillatory term over these triangular panels, the following criterion is defined: $\rho_{0}=\frac{M M}{d_{\max }}$ Where $M$ is the collocation point (field point) and $M^{\prime}$ is the center of gravity of the panel where $N$ has to be integrated (Figure 3(a)), and $d_{\max }$ corresponds to the largest side of the panel. Three cases have been considered:

- If $\rho_{0} \geq 2$, a seven-point Gauss integration method is performed over the triangular panel;

- If $1<\rho_{0}<2$, the triangular panel is divided into four triangular panels following Figure 3(b); a seven-point Gauss integration method is then performed over the new panels;

- If $\rho_{0} \leq 1$ the triangular panel is also divided into four new triangular panels and new criteria on: $\rho_{0_{i}}=\frac{M M_{i}^{\prime}}{d_{\max }}$ for the four values of subscript $i$ are applied:

- If $\rho_{0}^{i}>1$, integration is done by the seven-point method;

- If $\rho_{0}^{i}<1$, the panel is divided again into four new panels 
and on each new panel integration is done by the sevenpoint method.

The seven-point rule of degree 5 is given by ([19]):

$$
\begin{gathered}
\iint_{S} N \cdot d S= \\
\frac{A_{T}}{40}\left[\left(9 N_{0}\right)+\frac{(155-\sqrt{15})\left(N_{1}^{\prime}+N_{2}^{\prime}+N_{3}^{\prime}\right)}{30}\right. \\
\left.+\frac{(155+\sqrt{15})\left(N_{1}^{\prime \prime}+N_{2}^{\prime \prime}+N_{3}^{\prime \prime}\right)}{30}\right]
\end{gathered}
$$

where $N_{0}, N_{i}^{\prime}$ and $N_{i}^{\prime \prime}$ represent the amount of function $N$ between the field point and the points $x_{0}, x_{i}^{\prime}$ and $x_{i}^{\prime \prime}$ respectively of $T$ defined as:

$$
\begin{gathered}
x_{0}=\frac{x_{1}+x_{2}+x_{3}}{3}, \\
\vec{x}_{i}^{\prime}=\frac{\vec{x}_{0}(6-\sqrt{15})}{7}+\frac{\vec{x}_{i}(\sqrt{15}+1)}{7}, \\
\vec{x}_{i}^{\prime \prime}=\frac{\vec{x}_{0}(6+\sqrt{15})}{7}-\frac{\vec{x}_{i}(\sqrt{15}-1)}{7}
\end{gathered}
$$

\section{III) OSCILLATORY FAR FIELD TERM:}

This term can be expanded as:

$$
\begin{gathered}
W(X)=(-4 v) H(X) \int_{-\infty}^{+\infty} \operatorname{Im}\left\{\operatorname { e x p } \left[Z\left(1+t^{2}\right)\right.\right. \\
\left.\left.+i(X+Y t) \sqrt{1+t^{2}}\right]\right\} d t
\end{gathered}
$$

where Im denotes for the imaginary part. By defining the function $H(X, t)=\exp \left[Z p^{2}+i(X+Y t) p\right]$ with $p=\sqrt{1+t^{2}}$. This term and its gradient can be written as:

$$
\begin{gathered}
W(X)=H(X) \int_{-\infty}^{+\infty} \operatorname{Im}\{\mathrm{H}(\mathrm{X}, \mathrm{t})\} d t \\
W_{X}(X)=\int_{-\infty}^{+\infty} \operatorname{Re}[p H(X, t)] d t \\
W_{Y}(X)=\int_{-\infty}^{+\infty} \operatorname{Re}[p t H(X, t)] d t \\
W_{Z}(X)=\int_{-\infty}^{+\infty} \operatorname{Re}\left[p^{2} H(X, t)\right] d t
\end{gathered}
$$

Numerical integration of eq. (39) is troublesome due to the oscillatory behavior of the integrands increasing as $Z$ decreases.

Boundary integration is performed analytically to compute the far-field velocity potential. The method has been developed in Hendrix and Noblesse [6] to compute symmetrical flows. Below it is provided formulas for evaluating the integrals on $W$ and its gradient, which are obtained without taking into account any flow symmetry, and are therefore valid for lifting flows. In fact the 2 main objects that should be computed are:

$$
\begin{aligned}
I=\iint_{S} W n_{x} d s= & \int_{-\infty}^{\infty} d t \sum_{j=1}^{n_{j}} \iint_{S_{j}} \operatorname{Im}\{H(X, t)\} d s \\
J_{i}=\iint_{S_{j}} W_{n} d s= & \int_{-\infty}^{\infty} p\left[\left(-n_{x j}\right.\right. \\
& \left.-n_{y j} t\right) \operatorname{Re} \iint_{S_{j}} H(X, t) d s \\
& \left.+n_{z j} p \operatorname{Im} \iint_{S_{j}} H(X, t) d s\right] d t
\end{aligned}
$$

The integral $\iint_{S_{j}} H(X, t) d s$ (where $H$ is given earlier) can be computed analytically, following Hendrix \& Noblesse [6]. For a triangular panel $j$ (with area $\Delta S_{j}$ ) defined by its nodes $X_{1}^{\prime}, X_{2}^{\prime}, X_{3}^{\prime}$ and and for the flow observation point given by $X$, we obtain:

$$
\begin{aligned}
& \iint_{S_{j}} H(X, t) d s=\iint_{S_{j}} \exp (A) d s=\frac{2 \Delta S_{j}}{A_{3}-A_{2}} . \\
& {\left[\frac{\exp \left(A_{3}\right)-\exp \left(A_{1}\right)}{A_{3}-A_{1}}-\frac{\exp \left(A_{2}\right)-\exp \left(A_{1}\right)}{A_{2}-A_{1}}\right]}
\end{aligned}
$$

Where: $A_{k}=Z_{k} p^{2}+i\left(X_{k}+\right.$ :

It must be kept in mind that this oscillatory part of Green's function is present only if and this condition must be taken into account in the computations

Thus, the previous integrals are single ones over $t$. For a given collocation point, only one integration on $\mathrm{W}$ has to be computed, integration over the total body area being performed analytically, instead of computing a single integral over $t$ a number of times equal to the number of panels multiplied by the number of Gauss points on the panel in the method developed in the previous section. Concerning the integral over the gradient, for one collocation point, it has to be computed one integral over the panel area instead of as many integrals as the number of Gauss points. Numerical detail calculations of the all integrals presented in this paper can be found in [25-26].

\section{NUMERICAL RESULTS AND VALIDATION}

\section{TWO-DIMENSIONAL CYLINDER EXPOSED TO A UNIFORM FLOW:}

In this section, the results are presented for a $2 \mathrm{D}$ cylinder that are exposed to a uniform flow \& then compare them with the exact solutions. (is the number of elements that are applied for discretizing the boundary and is the cylinder radius). In the tables 1 and 2 the value of velocity potential at nodal points for 10 and 20 elements and in constant and linear elements are shown. 
Table 1 . The values of velocity potential at given nodal points of a $2 \mathrm{D}$ cylinderconstant element

(a: for $(n=10)$ and $b:$ for $(n=20))$

(a)

\begin{tabular}{|c|c|c|c|}
\hline $\mathrm{x} / \mathrm{a}$ & Calculated & Analytic & Relative Error \\
\hline 0.904508 & 1.780076 & 1.809017 & 0.015998 \\
\hline 0.559017 & 1.100148 & 1.118034 & 0.015998 \\
\hline $5.55 \mathrm{E}-17$ & $2.54 \mathrm{E}-11$ & $1.11 \mathrm{E}-16$ & ----- \\
\hline-0.559020 & -1.100150 & -1.118030 & 0.015992 \\
\hline-0.904510 & -1.780080 & -1.809020 & 0.015998 \\
\hline-0.904510 & -1.780080 & -1.809020 & 0.015998 \\
\hline-0.559020 & -1.100150 & -1.118030 & 0.015992 \\
\hline$-1.67 \mathrm{E}-16$ & $2.54 \mathrm{E}-11$ & $-3.33 \mathrm{E}-16$ & ------ \\
\hline 0.559017 & 1.100148 & 1.118034 & 0.015998 \\
\hline 0.904508 & 1.780076 & 1.809017 & 0.015998 \\
\hline
\end{tabular}

(b)

\begin{tabular}{|c|c|c|c|}
\hline $\mathrm{x} / \mathrm{a}$ & Calculated & Analytic & Relative Error \\
\hline 0.975528 & 1.942999 & 1.951057 & 0.004130 \\
\hline 0.880037 & 1.752805 & 1.760074 & 0.004130 \\
\hline 0.698401 & 1.391034 & 1.396802 & 0.004129 \\
\hline 0.448401 & 0.893099 & 0.896802 & 0.004129 \\
\hline 0.154508 & 0.307741 & 0.309017 & 0.004129 \\
\hline-0.154510 & -0.307740 & -0.309020 & 0.004142 \\
\hline-0.448400 & -0.893100 & -0.896800 & 0.004126 \\
\hline-0.698400 & -1.391030 & -1.396800 & 0.004131 \\
\hline-0.880040 & -1.752800 & -1.760070 & 0.004131 \\
\hline-0.975530 & -1.943000 & -1.951060 & 0.004131 \\
\hline-0.975530 & -1.943000 & -1.951060 & 0.004131 \\
\hline-0.880040 & -1.752800 & -1.760070 & 0.004131 \\
\hline-0.698400 & -1.391030 & -1.396800 & 0.004131 \\
\hline-0.448400 & -0.893100 & -0.896800 & 0.004126 \\
\hline-0.154510 & -0.307740 & -0.309020 & 0.004142 \\
\hline 0.154508 & 0.307741 & 0.309017 & 0.004129 \\
\hline 0.448401 & 0.893099 & 0.896802 & 0.004129 \\
\hline 0.698401 & 1.391034 & 1.396802 & 0.004129 \\
\hline 0.880037 & 1.752805 & 1.760074 & 0.004130 \\
\hline 0.975528 & 1.942999 & 1.951057 & 0.004130 \\
\hline
\end{tabular}

Table 2. The values of velocity potential at given nodal points of a $2 \mathrm{D}$ cylinderlinear elements

(a: for $(n=10)$ and $b:$ for $(n=20))$

(a)

\begin{tabular}{|c|c|c|c|}
\hline $\mathrm{x} / \mathrm{a}$ & Calculated & Analytical & Relative Error \\
\hline 1.0000000000 & 2.0000000911 & 2.0000000000 & 0.0000000455 \\
\hline 0.8090169944 & 1.6180340798 & 1.6180338987 & 0.0000001119 \\
\hline 0.3090169944 & 0.6180340798 & 0.6180339887 & 0.0000001474 \\
\hline-0.3090169944 & -0.6180338977 & -0.6180339887 & 0.0000001472 \\
\hline-0.8090169944 & -1.6180338977 & -1.6180339887 & 0.0000000562 \\
\hline-1.0000000000 & -1.9999999089 & -2.0000000000 & 0.0000000455 \\
\hline-0.8090169944 & -1.6180338977 & -1.6180339887 & 0.0000000562 \\
\hline-0.3090169944 & -0.6180338977 & -0.6180339887 & 0.0000001472 \\
\hline 0.3090169944 & 0.6180340798 & 0.6180339887 & 0.0000001474 \\
\hline 0.8090169944 & 1.6180347980 & 1.6180339887 & 0.0000005002 \\
\hline
\end{tabular}

(b)

\begin{tabular}{|c|c|c|c|}
\hline $\mathrm{x} / \mathrm{a}$ & Calculated & Analytical & Relative Error \\
\hline 1.0000000000 & 2.0000001392 & 2.0000000000 & 0.0000000696 \\
\hline 0.9510565163 & 1.9021131718 & 1.9021130326 & 0.0000000732 \\
\hline 0.8090169944 & 1.6180341279 & 1.6183398870 & 0.0001889338 \\
\hline 0.5877852523 & 1.1755706438 & 1.1755705046 & 0.0000001184 \\
\hline
\end{tabular}

\begin{tabular}{|c|c|c|c|}
\hline $\mathrm{x} / \mathrm{a}$ & Calculated & Analytical & Relative Error \\
\hline 0.3090169944 & 0.6180341279 & 0.6180339887 & 0.0000002252 \\
\hline 0.0000000000 & 0.0000001392 & 0.0000000000 & ------- \\
\hline-0.3090169944 & -0.6180338496 & -0.6180339887 & 0.0000002251 \\
\hline-0.5877852523 & -1.1755703654 & -1.1755705046 & 0.0000001184 \\
\hline-0.8090169944 & -1.6180338496 & -1.6180339887 & 0.0000000860 \\
\hline-0.9510565163 & -1.9021128935 & -1.9021130326 & 0.0000000731 \\
\hline-1.0000000000 & -1.9999998609 & -2.0000000000 & 0.0000000695 \\
\hline-0.9510565163 & -1.9021128935 & -1.9021130326 & 0.0000000731 \\
\hline-0.8090169944 & -1.6180338496 & -1.6180339887 & 0.0000000860 \\
\hline-0.5877852523 & -1.1755703654 & -1.1755705046 & 0.0000001184 \\
\hline-0.3090169944 & -0.6180338496 & -0.6180339887 & 0.0000002251 \\
\hline 0.0000000000 & 0.0000001392 & 0.0000000000 & ------- \\
\hline 0.3090169944 & 0.6180341279 & 0.6180339887 & 0.0000002252 \\
\hline 0.5877852523 & 1.1755706438 & 1.1755705046 & 0.0000001184 \\
\hline 0.8090169944 & 1.6180341279 & 1.6183398870 & 0.0001889338 \\
\hline 0.9510565163 & 1.9021131718 & 1.9021130326 & 0.0000000732 \\
\hline
\end{tabular}

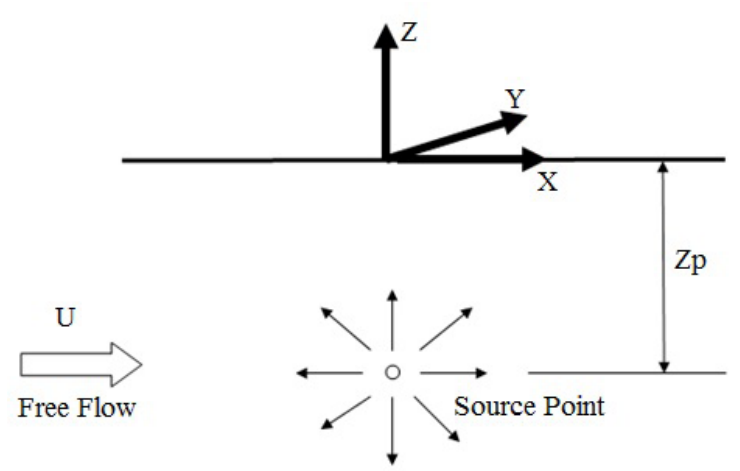

Fig. 4. Schematic of a moving submerged source

\section{MOTION OF A SUBMERGED SOURCE IN DEEP WATER:}

The first step in evaluation and investigation of free surface waves is to test the accuracy of green function of the source which we want to use. So, in the first part the free surface waves due to motion of a submerged source is shown and is investigated which show a good agreement with other literature results. In figure 4 the schematic of the motion of a moving submerged source is shown.

In figure 5 wave pattern and contour of a submerged source in depth $2 \mathrm{~m}$ and with velocity $1 \mathrm{~m} / \mathrm{s}$ is shown. The transverse and divergent waves are apparent in this pattern. 


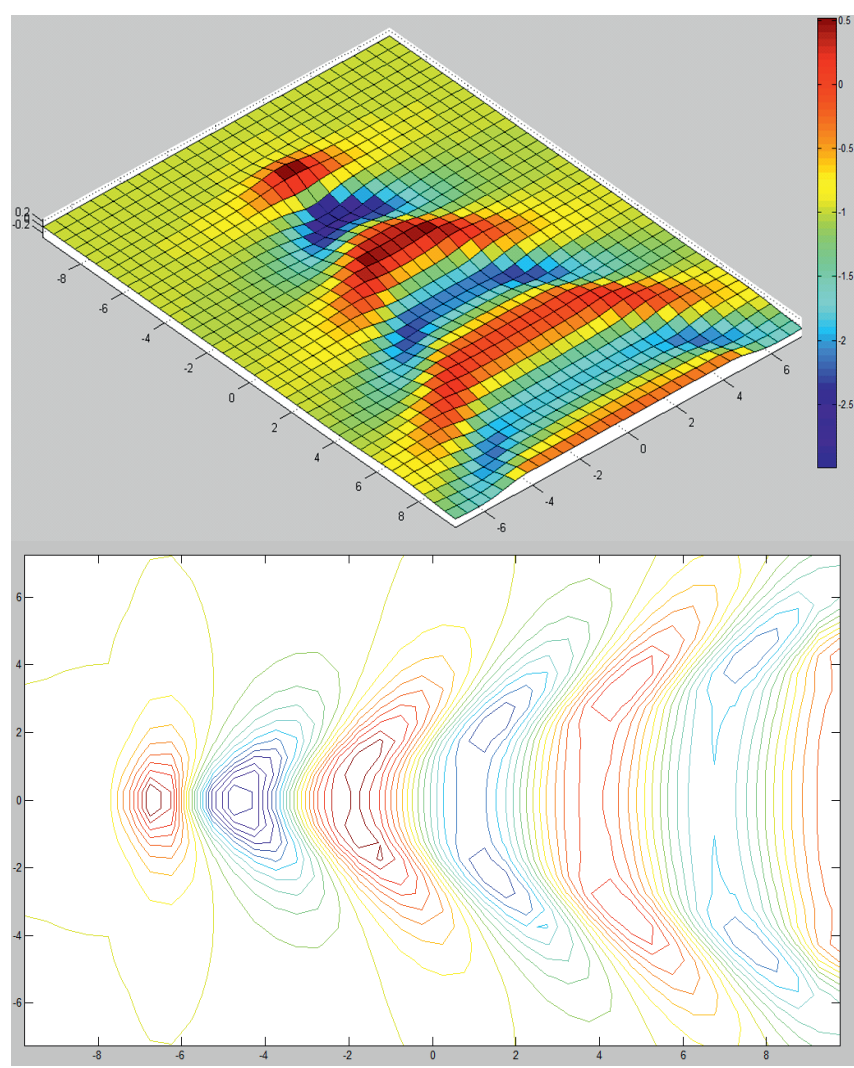

Fig. 5. Wave pattern and contour of a submerged source in depth $2 m$ and with velocity $1 \mathrm{~m} / \mathrm{s}(\mathrm{Fn}=0.22)$

In figure 6 the wave pattern and contour of previous situation with 300 and 1200 free surface elements are shown and as could be seen, both results are the same and this means that the results are independent of the number of elements.

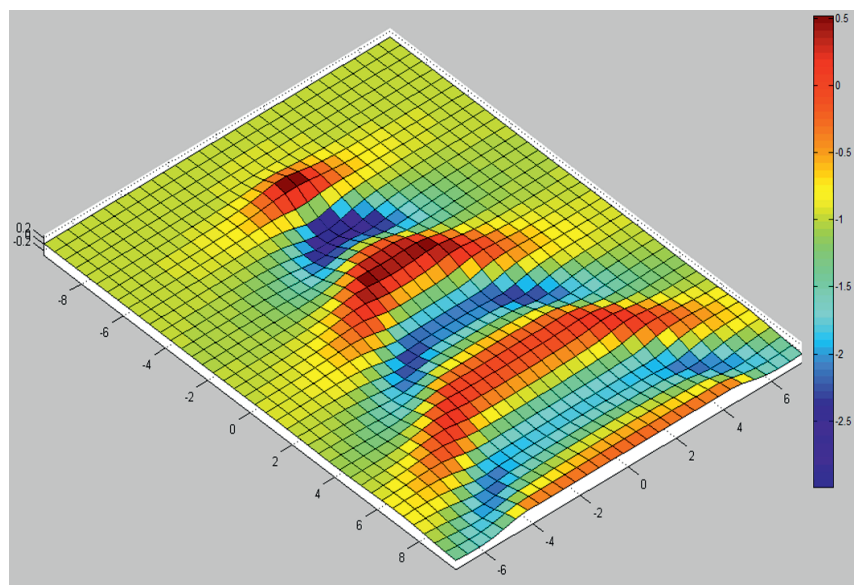

(a)

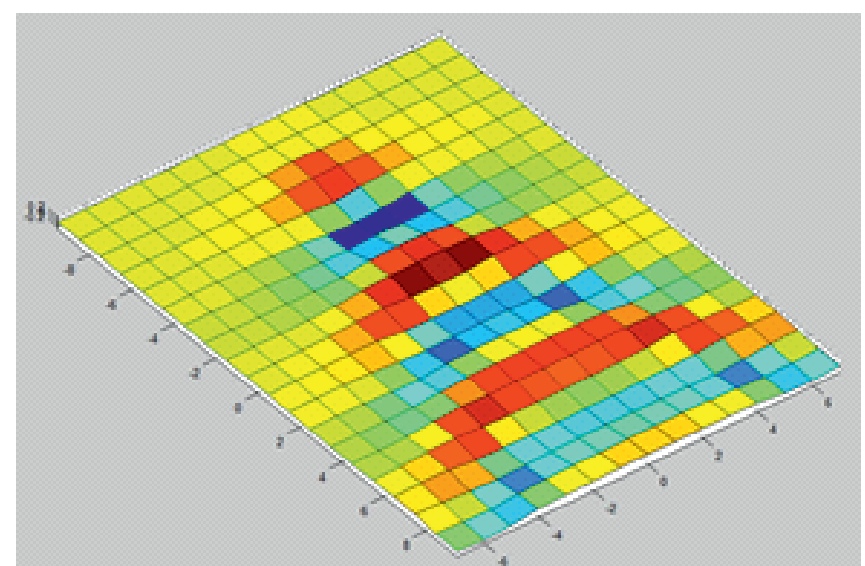

(b)

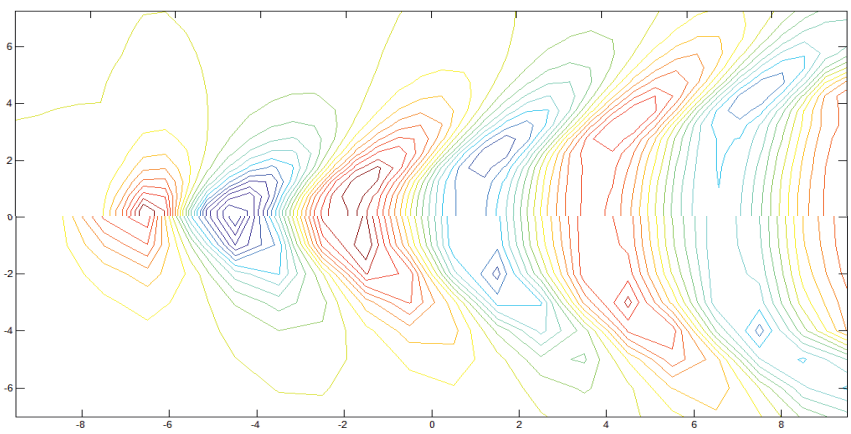

(c)

Fig. 6. Wave pattern of a source in $Z=-2 m$ and $U=1 \mathrm{~m} / \mathrm{s}$ ( $F n=0.22)$, (with (a) 1200 and with (b) 300 free surface elements) and wave contour with 1200 element in upper part and 300 elements in lower part of $(c)$

In Figure 7 the wave profile in various transverse distances from source are shown and it could be seen that the wave amplitude decreases with increasing transverse distance from the source.

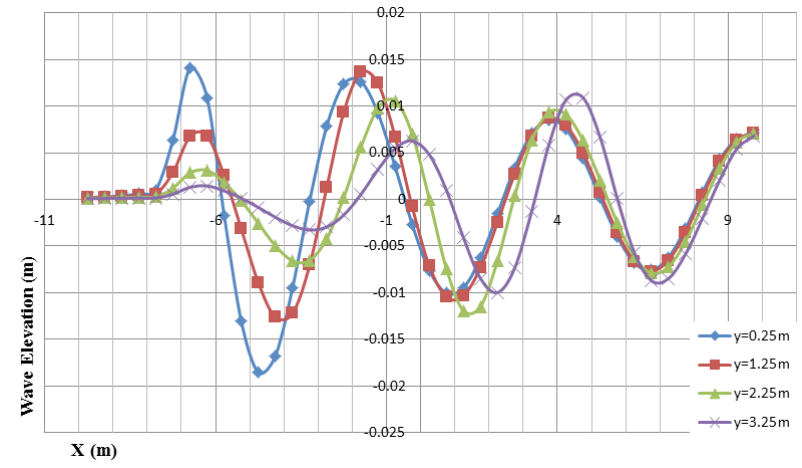

Fig. 7. Wave profile in various transverse distances from source

In figure 8 the wave pattern of 2 parallel moving source is shown and compared to the result of Parau, \& Vanden [19].

The wave pattern changes with changing Froude number. In Figure 9, the wave patterns in different situation are shown. As shown in Figure 9 in low Froude numbers the transverse wave is dominant part of whole wave pattern but with increasing Froude number, the transverse waves are vanished and the divergent waves increase and in high Froude number, the wave pattern totally changes. 


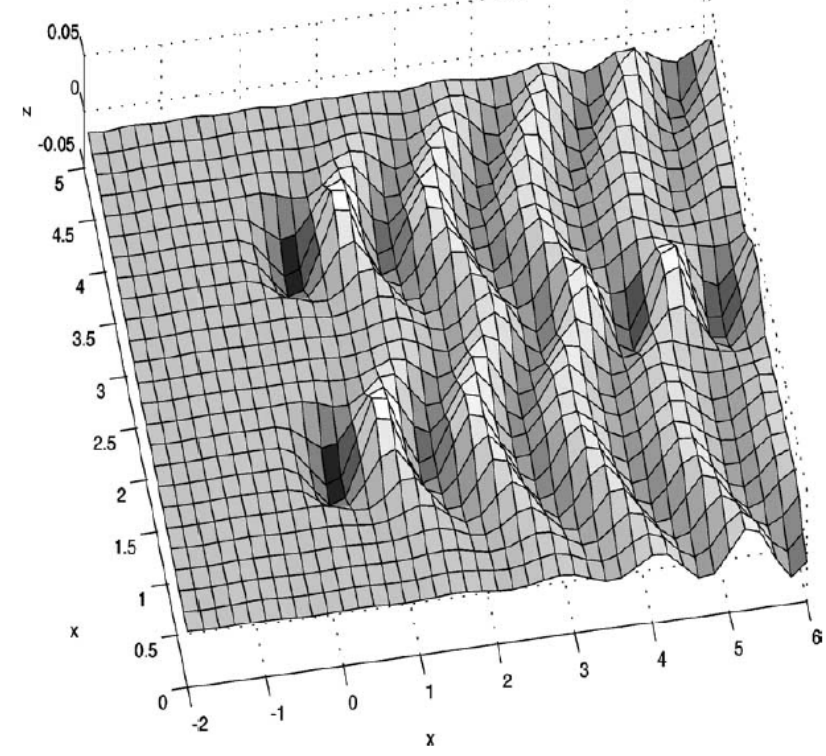

(a)

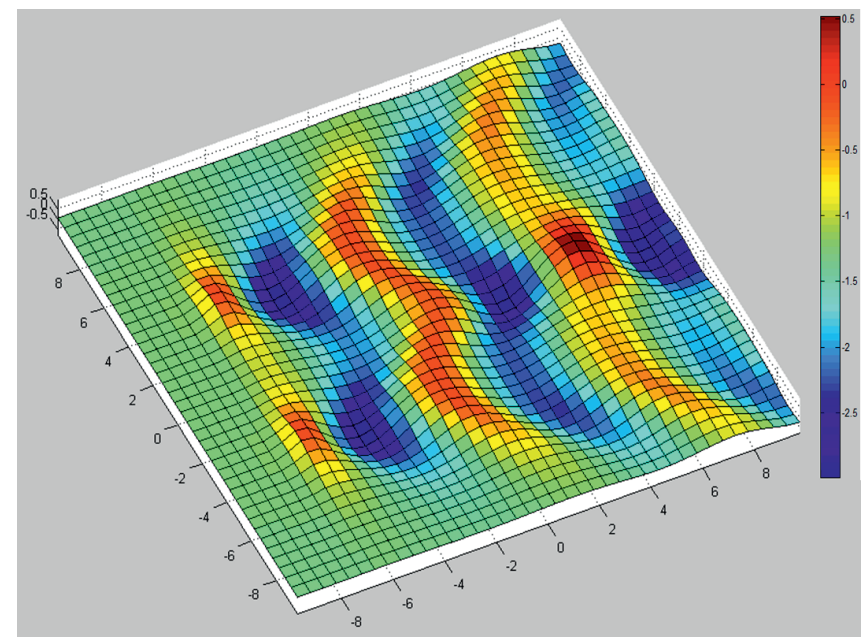

(b)

Fig. 8. Wave pattern of 2 moving source (Fn=0.4). (a: from reference [19] and $b$ : from the present method)

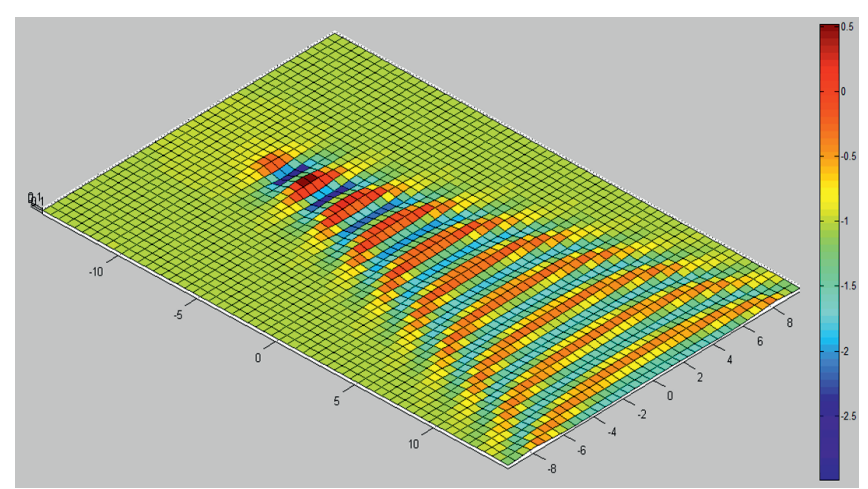

(a)

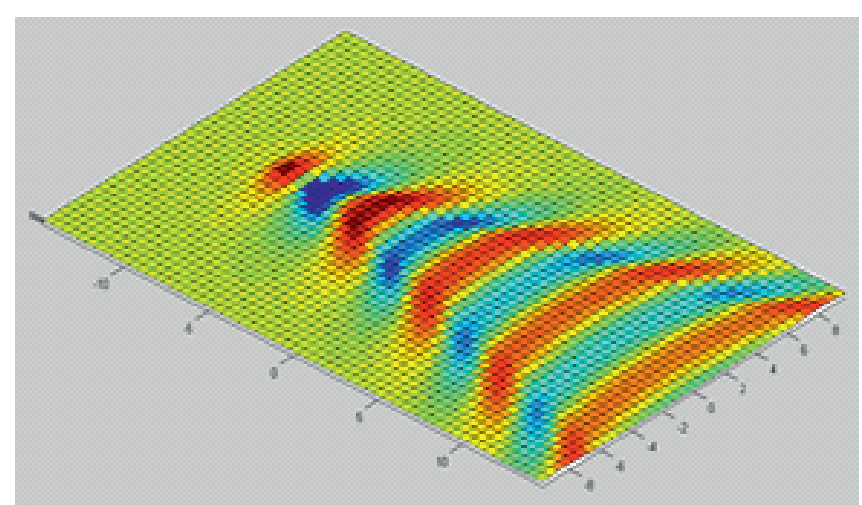

(b)

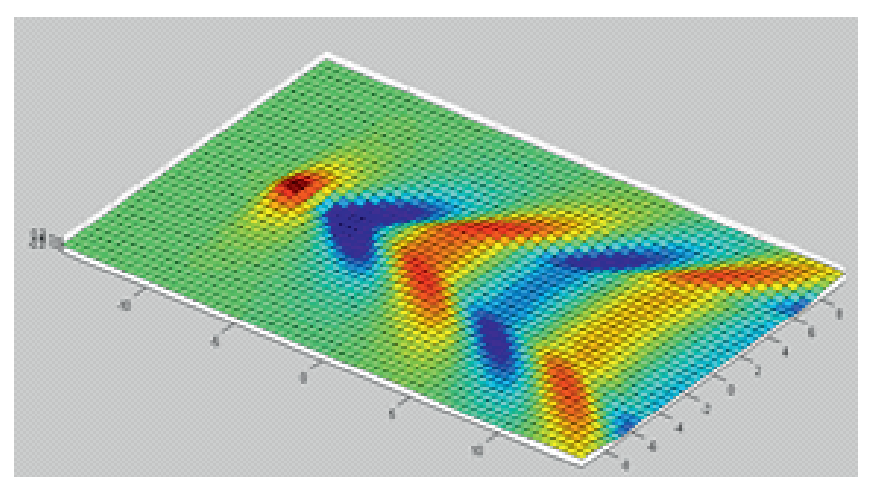

(c)

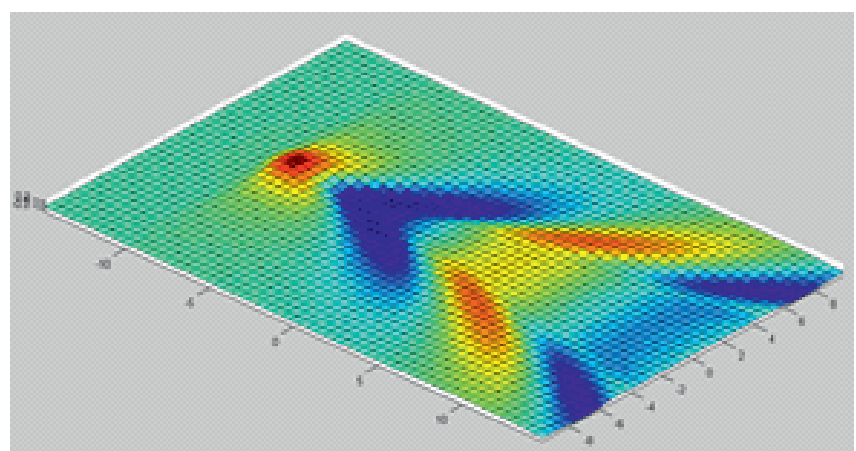

(d)

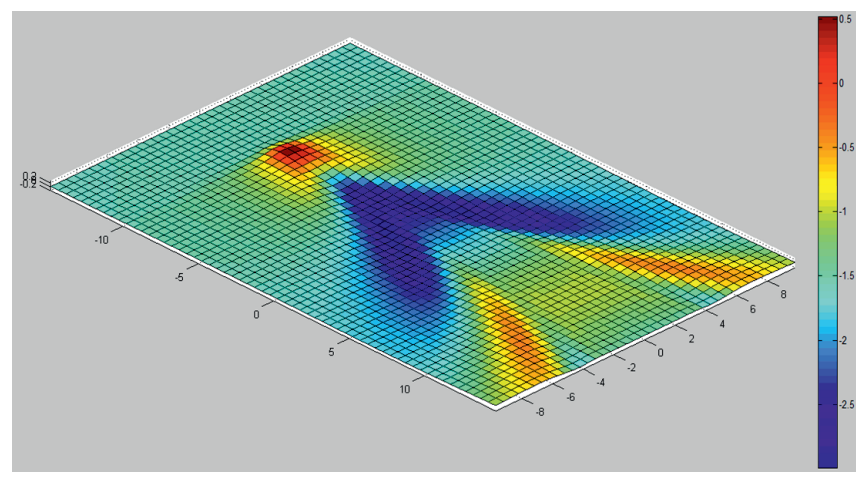

(e)

Fig. 9. Wave patterns of submerged source in $Z=-3 \mathrm{~m}$ with $U=1,2,3,4$ and 4.5 in $A, B, C, D$ and $E$, respectively. $(F n=0.18,0.36,0.54,0.72$ and 0.8$)$ 


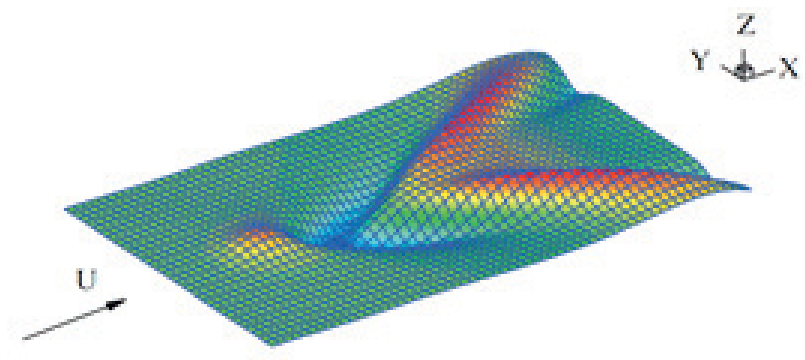

(a)

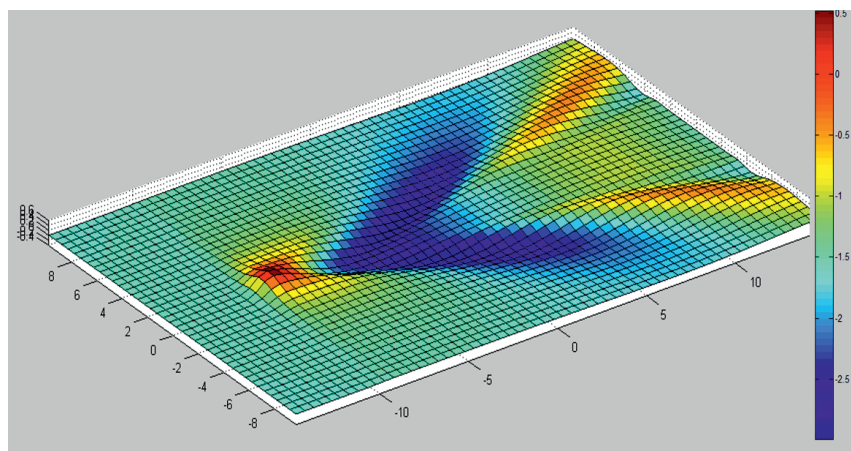

(b)

Fig. 10. Wave patterns of a submerged source in $Z=-3 \mathrm{~m}$ with $U=4.5 \mathrm{~m} / \mathrm{s}$ ( $F n=0.8)$. (a: from reference [23] and $b$ : from the present paper)

In Figure 10, the wave pattern in $\mathrm{Fn}=0.8$ is shown and compared to the results of Uslu \& Bal [20].

\section{MOTION OF WIGLEY HULL AND SUBMERGED SPHERE AND ELLIPSOID IN DEEP WATER:}

Figure 11 shows the wave pattern due to motion of a submerged sphere (with radius 1 , in depth $2 \mathrm{~m}$ and velocity $1 \mathrm{~m} / \mathrm{s}$.

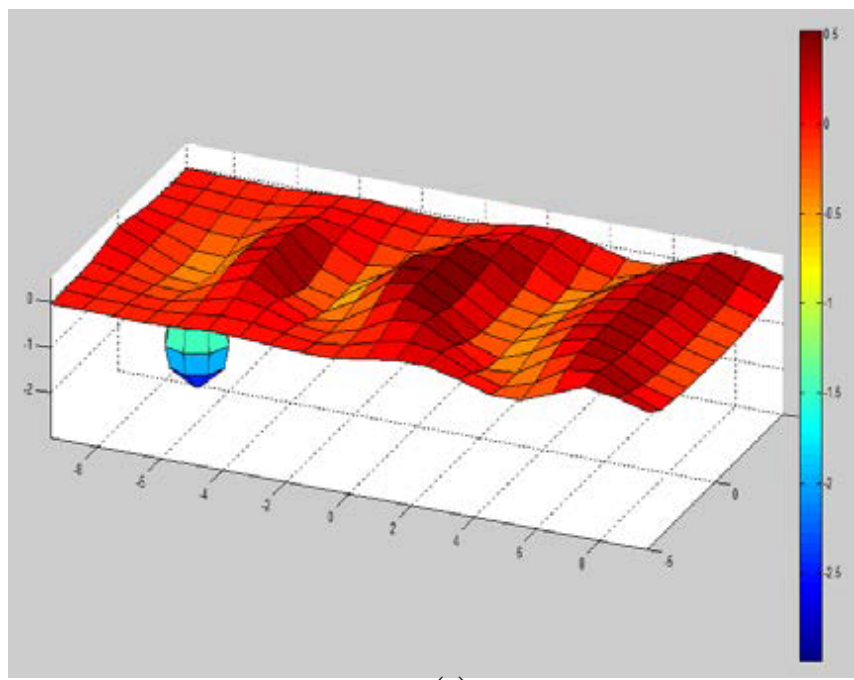

(a)

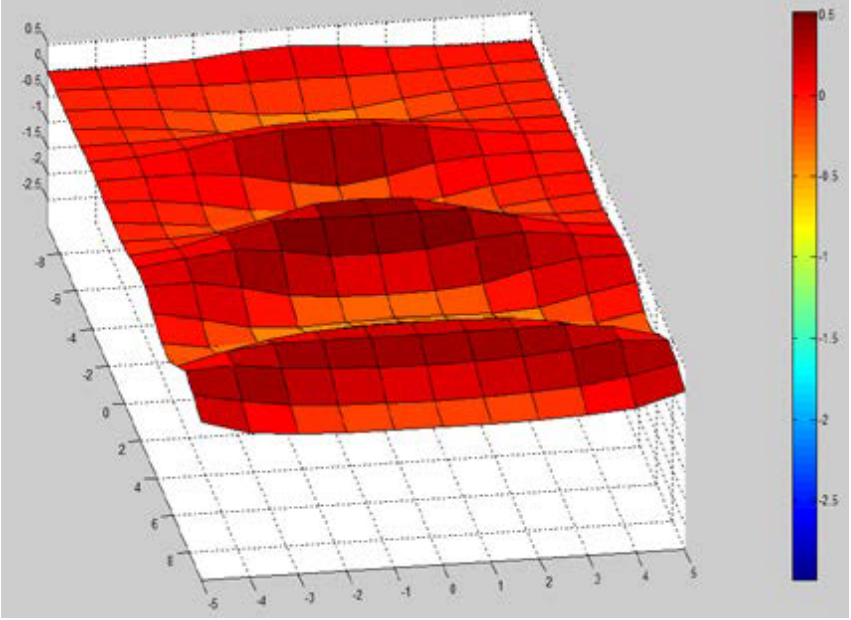

(b)

Fig. 11. Wave pattern of a submerged sphere in $Z=-2 \mathrm{~m}$ with $U=1 \mathrm{~m} / \mathrm{s}$, $(F n=0.22)$

The effect of sphere velocity on the wave profile is shown in Figure 12, and it illustrates that wave amplitude increase with increasing velocity.

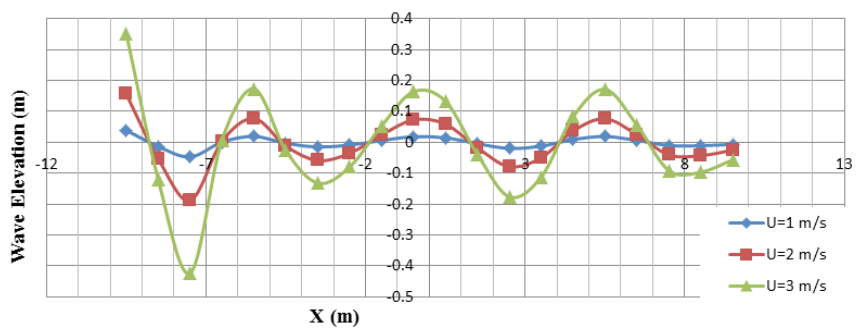

Fig. 12. Effect of sphere velocity on the wave profile

In Figure 13, the wave pattern of a submerged ellipsoid with large to small diameter ratio 4 in depth $2 \mathrm{~m}$ and velocity $3 \mathrm{~m} / \mathrm{s}$ are shown. 

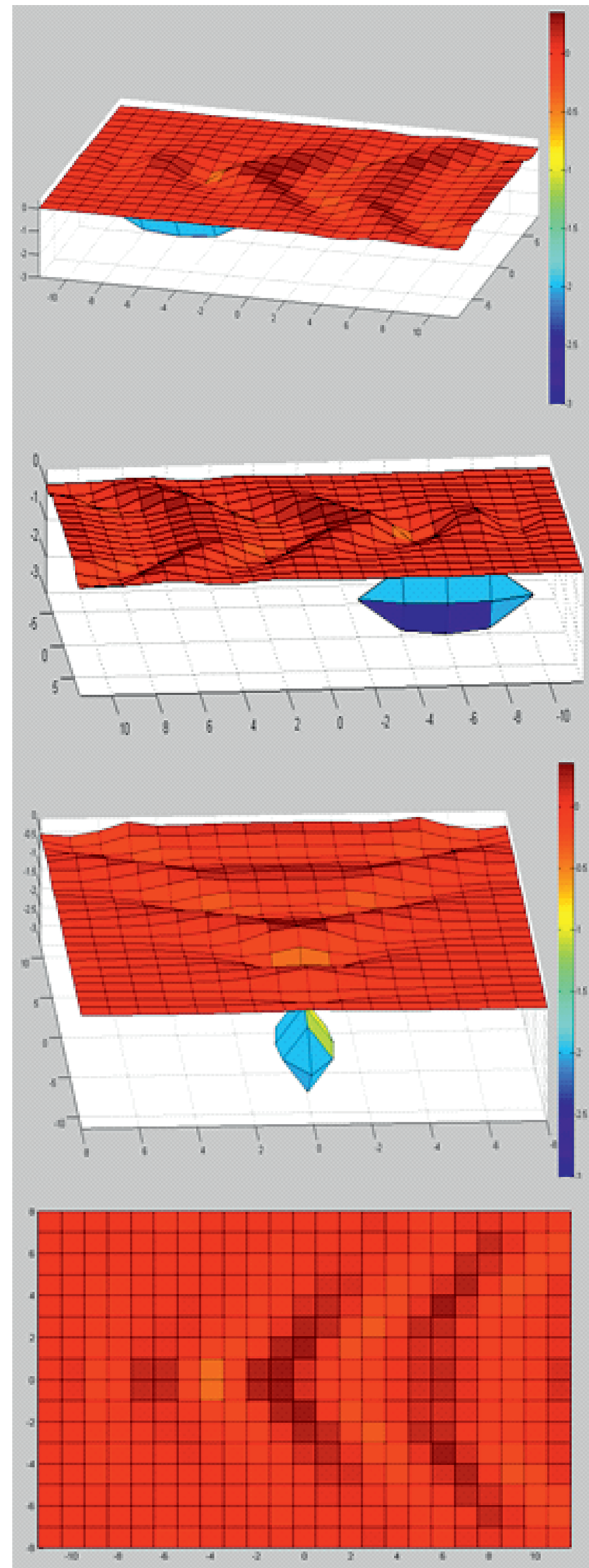

Fig. 13. Wave pattern of a submerged ellipsoid in $Z=-2 \mathrm{~m}$ with $U=3 \mathrm{~m} / \mathrm{s}$, $(F n=0.47)$
Figure 14 shows the effect of submergence depth over the wave profile. It depicts that with increasing submergence depth, the wave amplitude decrease and as could be seen from $\mathrm{Z}=-6 \mathrm{~m}$, approximately it doesn't create any wave on free surface. It means that in depth of 6 meter and below, we can analyze the motion of this ellipsoid without considering the free surface effect and we can use just term for green function.

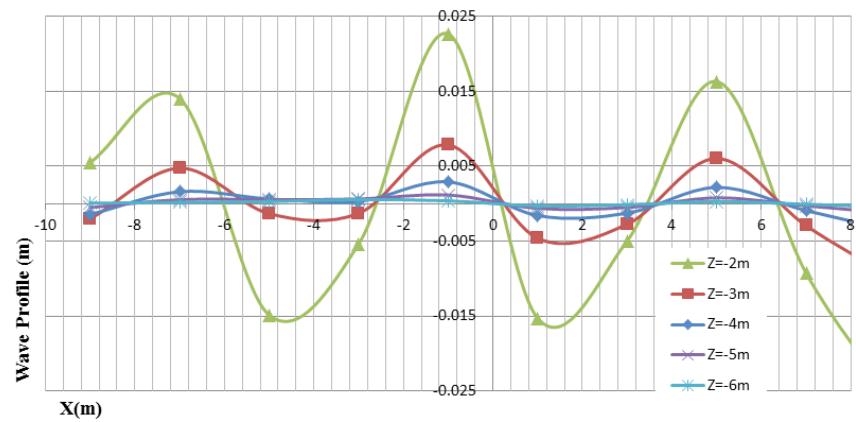

Fig. 14. Wave profile of a submerged ellipsoid in various depths with $U=1 \mathrm{~m} / \mathrm{s}$

A Wigley hull is recognized with its body equation which is $y= \pm \frac{B}{2}\left[1-\left(\frac{z}{T}\right)^{2}\right]\left[1-\left(\frac{x}{0.5 L}\right)^{2}\right]$ where $B$ is hull beam, $L$ is body length and $T$ is draft. In figure 15 , the wave pattern of a Wigley hull with ratios $\mathrm{L} / \mathrm{B}=4, \mathrm{~B} / \mathrm{T}=1$ and $\mathrm{U}=2.5 \mathrm{~m} / \mathrm{s}$ is shown.

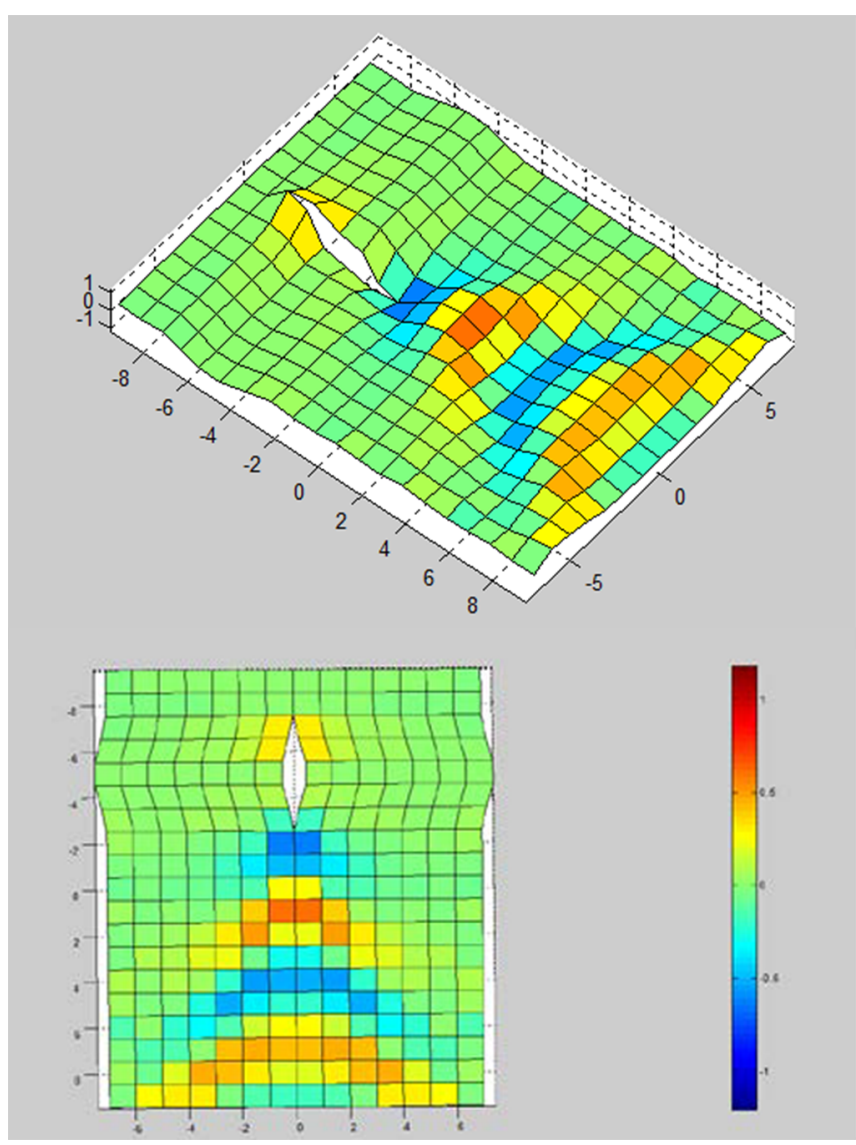

Fig. 15. Wave pattern of a Wigley hull with $U=2.5 \mathrm{~m} / \mathrm{s}$ 


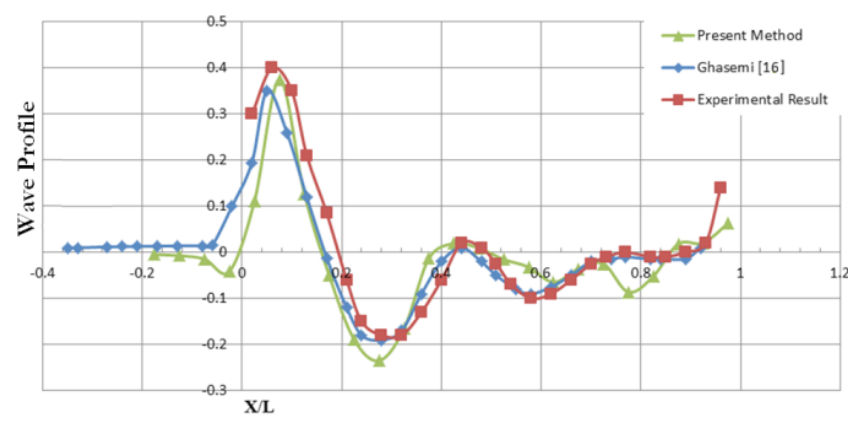

Fig. 16. Wave profile of a Wigley hull $U=2.5 \mathrm{~m} / \mathrm{s}(F n=0.25)$

The wave profile of a Wigley hull with ratios $\mathrm{L} / \mathrm{B}=10, \mathrm{~B} /$ $\mathrm{T}=1.6$ and $\mathrm{U}=2.5 \mathrm{~m} / \mathrm{s}$ is shown in Figure 16, and compared to experimental data and results of by Ghassemi et al. [16], that shows good agreement between them.

\section{CONCLUSIONS}

In this paper, the numerical evaluation of the hydrodynamic characteristics of submerged and surface piercing moving bodies are presented. In results for 2D cylinder, more accuracy of linear elements in comparison of constant elements is apparent. For example the relative error of constant elements are in order of whereas in linear elements are in order of, although it also depends on the number of elements. Then in $3 \mathrm{D}$ bodies, the results obtained by a potential-based panel method to calculate free surface waves induced by submerged or surface-piercing bodies have been presented. This method uses the distribution of Kelvin-Havelock sources for modeling the body and this method enabling the flow to be calculated without any discretization of the free surface leading to automatic satisfaction of the radiation and linearized freesurface boundary conditions. Computations of the oscillating and non-oscillating terms of Green's function are performed by accurate methods.

This method gives suitable solution and the agreement between the results of experimental measurements and the present numerical method is satisfactory and indicates the robustness and practical worthiness of the proposed method. Since the used code was written in MATLAB software, the running process took much time so the elements didn't selected too much on the body surface and this is the main reason for the little deviation from experimental and literature results.

Final practical application of this method can be found the relation between of the wave length and body speed, like this formula $\lambda=2 \pi V^{2} / g$. For example; if any submerged body is moving under free surface generating wave, we can measure the wave length and find the body's speed.

Further works must be devoted to the precision of the boundary integrals for source and field points close to the free surface, particularly when the Froude number increases. Finally, it seems to be interesting to develop in the future a second-order method for calculating the nonlinear free surface problem with high accuracy.

\section{REFERENCES}

1. Andrew, R. N., Baar, J. J. M. and Price, W.G. "Prediction of ship wave-making resistance and other steady flow parameters using Neumann-Kelvin theory”, Proc., Royal Institution of Naval Architects, 1987.

2. Newman, J. N., "Evaluation of the wave-resistance Green function, Part 1-the double integral”, Journal of Ship Research, 31(2), 1987a, pp.79-90.

3. Newman, J. N., "Evaluation of the wave-resistance Green function, Part 2-the single integral on the centerplane", Journal of Ship Research, 31(3), 1987b, pp.145-150.

4. Chen, C. Y. and Noblesse, F., "Comparison between theoretical predictions of wave resistance and experimental data for the Wigley hull”. Journal of Ship Research, 27, 4, 1983, pp.215-226.

5. Telste, J. G. and Noblesse, F., "The non-oscillatory nearfield in the Green function for steady flow about a ship", Proceeding 17th Symposium of Naval Hydrodynamics, The Hague, 1988, 39-52.

6. Hendrix, D. and Noblesse, F., "Recipes for computing the steady free surface flow due to a source distribution", Journal of Ship Research, 36(4), 1992, pp.346-359.

7. Bulgarelli, U. P., Lugni, C. and Landrini, M., "Numerical Modeling of Free Surface Flows in Ship Hydrodynamics", International Journal for Numerical Methods in Fluids, 43, 2003, pp.465-481.

8. Tulin, M. P., "Reminiscences and Reflections: Ship Waves, 1950-2000”. Journal of Ship Research, 49, 2005, pp.238- 246.

9. Larrson, L. and Baba, E., "Ship Resistance and Flow Computations". Advances in Marine Hydrodynamics, Computational Mechanics Publications, 1996; 1-76.

10. Gatchell, S., Hafermann, D., Jensen, G., Marzi, J. and Vogt, M., "Wave resistance computations-a comparison of different approaches", Proceedings of the 23rd Symposium on Naval Hydrodynamics, Val de Reuil, France, 2001.

11. Baar, J. J. M. "A three-dimensional linear analysis of steady ship motion in deep water". Ph.D. Dissertation, Brunel University, U.K., 1986.

12. Baar, J. J. M. and Price, W.G. "Evaluation of the wavelike disturbance in the Kelvin wave source potential", Journal of Ship Research., 32(1), 1988, pp44-53.

13. Cao, Y., Schultz, W. W. and Beck, R. F. “Three-dimensional desingularized boundary integral methods for potential 
problems", International Journal of Numerical Methods in Fluids, 12, 1991, pp785-803.

14. Hsin, C. Y. and Chou, S. K., "Applications of a hybrid boundary element method to the analysis of free surface flow around lifting and non-lifting bodies", Proceeding. of the 22nd Symposium on Naval Hydrodynamics, Washington D.C., U.S.A., 1998.

15. Yasko, M., "Boundary element method for a hydrofoil near the free surface". Engineering Analysis with Boundary Elements, 21, 1998, pp.191-194.

16. Ghassemi, H., Kohansal, A. and Ghamari, I., (2009) "Nonlinear free surface flows due to the lifting and nonlifting moving bodies" May, 2009, Proceeding of the 16th International Conference of the ISME, Tehran, Iran.

17. Ghassemi H. and Kohansal A. R., "Wave Generated by the NACA4412 Hydrofoil near Free Surface", Journal of Applied Fluid Mechanics, Vol. 6, No. 1, pp. 1-6, 2013.

18. Tuck, E., Scullen, D. and Lazauskas, L., "Wave patterns and minimum wave resistance for high-speed vessels" International 24th Symposium on Naval Hydrodynamics, Fukuoka, Japan, 2002.

19. Parau, E., and Vanden-Broeck, J. M., "Nonlinear twoand three-dimensional free surface flows due to moving disturbances", European Journal of Mechanics B/Fluids 21, 2002, pp.643-656.

20. Uslu, Y. and Bal, S., "Numerical prediction of wave drag of 2-d and 3-d bodies under or on a free surface" Turkish Journal Engineering Environment Science, 32, 2008, pp.177-188.

21. Javanmardi, M., Binns, J. R., Renilson, M.R. and Thomas, G., "The prediction of wave patterns at large distances from a moving body in a confined channel", 18th Australasian Fluid Mechanics Conf. Launceston, Australia, December 2012.

22. Sun, J., Lv, X., Liu, W., Ning, H. and Chen, X., "Research on a method of hull form design based on wave-making resistance optimization", Polish Maritime Research, 19(3), 2012, pp16-25.

23. Zakerdoost, H., Ghassemi H. and Ghiasi M., "Ship hull form optimization by evolutionary algorithm in order to diminish the drag", Journal Marine Science Applied (2013) 12: $170-179$.

24. Ozdemir, Y. H., Cosgun, T., Dogrul, A. and Barlas, B. “A numerical application to predict the resistance and wave pattern of KRISO container ship", Brodogradnja, 67(2), 2016.
25. Paris, F. and Canas J., "Boundary element method: fundamental and applications”, Oxford University Press, 1997.

26. Ghassemi, H. and Bakhtiari, M., "Boundary element method", Amirkabir Universty of Technology Publication, 2016.

\section{CONTACT WITH THE AUTHORS}

Hassan Ghassemi

e-mail:gasemi@aut.ac.ir

Faculty of Maritime Engineering AmirKabir University of Technology

Hafez Ave., Tehran

\section{IRAN}

Isar Ghamari

e-mail:isar.ghamari@ntnu.no

Department of Marine Technology Norwegian University of Science and Technology (NTNU) Trondheim,

\section{NORWAY}

Arash Ashrafi

e-mail:arashonline65@aut.ac.ir

Faculty of Maritime EngineeringAmirKabir University of Technology

Hafez Ave., Tehran

\section{IRAN}

